\title{
Francisco Raúl Carnese, 1941-2019
}

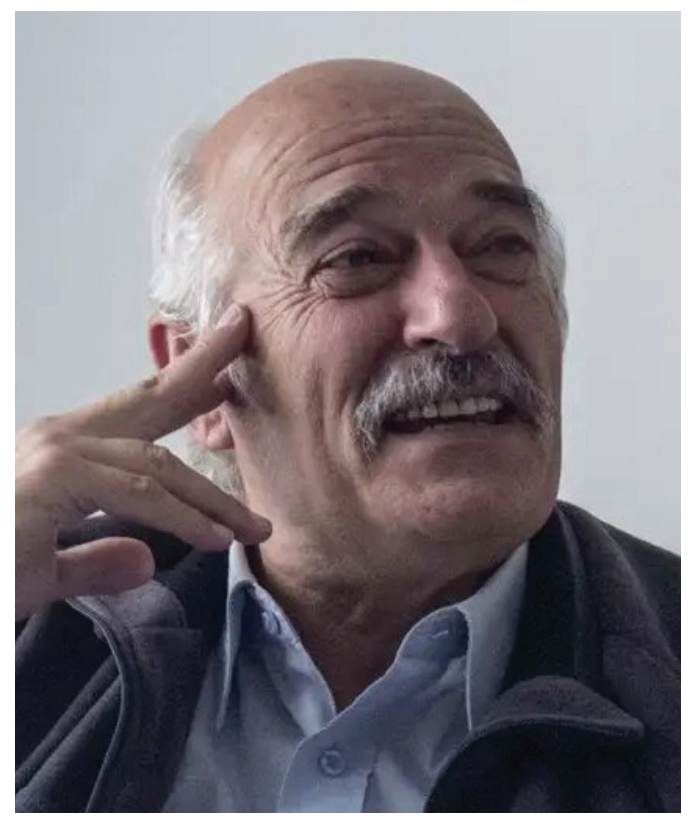

Foto de Soledad Torres Agüero. Ciclo Trayectorias, Colegio de Graduados en Antropología de la República Argentina. http://cga.org.ar/trayectorias-30-francisco-raul-carnese

El 14 de junio falleció Francisco Raúl Carnese, Raúl para todos lo que tuvimos la enorme suerte de conocerlo.

Nació en 1941 en Avellaneda, barrio que nutrió mucho de su historia, en la cual frecuentemente involucraba a su querido Independiente, su cancha pero también su biblioteca ("la tercera de Argentina", decía).

Cuando ingresó a la Universidad Nacional de La Plata (UNLP) lo hizo en la carrera de geología, inspirado por un profesor de merceología del secundario. Admiraba en ese docente del Joaquín V. González de Barracas, lo mismo que iba a insuflar en su vida, pasión por enseñar, por aprender, por indagar, por pensar por sí mismo. Para ver como el Dr. Carnese contaba su propia historia puede consultarse el excelente video que forma parte del Ciclo de Encuentros "Trayectorias" del Colegio de Graduados de Antropología (2013).

Raúl decía que no era esperable que un Perito Mercantil como él se planteara estudiar Antropología, pero luego de cursar esa asignatura decidió cambiar de carrera. Lamentablemente el plan de estudios y los profesores respondían en su mayoría a la Escuela Histórico Cultural, con un enfoque tipológico, y muchas veces de tinte racista. Esto lo molestaba sobremanera. Allí Raúl mostró su concepción y el aplomo que lo caracterizaría. Junto a otros estudiantes, entre los que estaba su entrañable amigo y compañero Héctor Pucciarelli y apoyados por el Profesor Rex González, trabajaron para la modificación del plan de estudios. La propuesta, que fue aprobada, incluía un cambio radical, el objetivo de la Antropología no debía ser meramente realizar una tarea taxonómica, abstrayendo a los grupos humanos de su historia, sino enfatizar la unidad de la ciencias antropológicas a partir del eje estructurante de la diversidad.

Raúl, como muchos de sus compañeras y compañeros, creía que la universidad no podía desentenderse de la sociedad y sus problemáticas. Había que ser buen estudiante pero también militar por un país más justo. En 1962 fue elegido delegado estudiantil al Consejo Académico de la Facultad de Ciencias Naturales y Museo (FCNyM) de la UNLP, recibiéndose en 1966 de Licenciado en Antropología (Orientación Biológica), doctorándose en 1971. Su tema de Tesis se denominó "Grupos Sanguíneos en Tejidos Humanos. Sus Implicancias Antropológicas". Quería analizar el poblamiento de América, pero desde una perspectiva innovadora, la genética serológica. Allí intentó responder al interrogante, hasta ese momento sin respuesta, de por qué, salvo unas pocas excepciones, los amerindios eran de grupo sanguíneos 0 y Rh positivo, teniendo en cuenta que en las poblaciones asiáticas estaban presentes los antígenos grupales sanguíneos A y B.

Fue uno de los propulsores del Proyecto Nueva Universidad (1973), por el cual se incluyó un curso inicial en el que los estudiantes asistían a un Ciclo de Formación de la Conciencia Nacional. El objetivo era conectar la educación superior con la realidad social. Con ese objetivo asumió como Secretario de Asuntos Académicos y luego como Decano de la FCNyM. En

doi:10.24215/18536387e009 
octubre de 1974 la UNLP fue intervenida por parte del Poder Ejecutivo Nacional siendo Raúl cesanteado, como muchos otros docentes. En 1975 se lo designó Profesor Adjunto de Biología General en la Universidad Nacional de Luján, pero fue nuevamente despedido al producirse el golpe de estado del 24 de marzo de 1976. Para conocer en detalle esta etapa de su vida académica puede consultarse el artículo de Bonomo y Prates (2019).

Debe dejar La Plata con su familia, instalándose en Buenos Aires. Durante toda la dictadura se mantuvo alejado de la facultad. Primero vendiendo casas prefabricadas, luego consiguiendo trabajo en la Fundación de Genética Humana (por un contacto con un ex-alumno, cuyo padre trabajaba allí), para lo que tuvo que reconvertirse de genetista de poblaciones en citogenetista. Posteriormente pasó a ocupar la Jefatura de esa especialidad en el Laboratorio del Hospital Italiano.

Ya en democracia se entera que el Profesor Rex González había sido nombrado Director del Museo Etnográfico. Decide ir a saludarlo. Rex le comenta que se iba a abrir el concurso de Antropología Biológica (FFyL, UBA). Raúl le dice que no puede presentarse, porque hace casi una década que estaba fuera del ámbito académico. Ante la insistencia de Rex, concursa y gana el cargo de Profesor Adjunto de Antropología Biológica y Paleoantropología de la Facultad de Filosofía y Letras de la Universidad de Buenos Aires (FFyL, UBA), y luego, en 1989, el de Profesor Titular de la misma cátedra.

Recién asumido realizó un cambio radical del programa de la materia, que hasta ese momento se enmarcaba en el historicismo-cultural. Propuso lineamientos innovadores que todavía están vigentes. A partir de una concepción que sitúa a la Antropología Biológica en un campo disciplinario en la intersección de las Ciencias Biológicas y Sociales, se incluyeron temas como microevolución, crecimiento y desarrollo, proceso de hominización, bioarqueología y análisis crítico de las clasificaciones raciales a la luz de los aportes de la genética de poblaciones.

Como Director de la Sección de Antropología Biológica inició varias líneas de investigación, como los estudios antropogenéticos en comunidades de pueblos originarios y de poblaciones cosmopolitas.

En los primeros como fue mencionado, ya en su doctorado se había propuesto analizar la genética de los primeros habitantes de nuestro país, a través de la determinación de la presencia de proteínas asociadas a los diferentes grupos sanguíneos $\mathrm{ABO}$. Con el mismo objetivo fue cómo en 2003 firma un convenio ECOS-Sud (ANPCyT) con la Universidad de Toulouse para el estudio paleogenético de individuos de grupos prehispánicos de Argentina. Se publica un trabajo original en el que no sólo se analiza el ADN sino también marcadores nucleares, que permitieron excluir la presencia de parentesco entre los individuos analizados. Luego se monta un laboratorio pionero en el país específicamente dedicado a desarrollar localmente estudios de ADN antiguo.

En los segundos, se determinaron los aportes de pueblos originarios y africanos al acervo génico de las poblaciones de varias ciudades de Argentina, y a partir de su detección tanto a nivel poblacional como individual, se analizaron críticamente las narrativas dominantes de nuestro país, donde se subestima o directamente niega su presencia.

Fue Miembro Fundador de la Asociación de Antropología Biológica Argentina, de la Sociedad Argentina de Genética y de la Asociación Latinoamericana de Antropología Biológica, de la que fue dos veces Presidente (1996 y 2006). Incansable, también fundó y dirigió por muchos años la Revista Argentina de Antropología Biológica, junto a Héctor Pucciarelli, su gran colega, amigo y compañero. Ambos trabajaron denodadamente para que la revista se convirtiera en un ámbito de referencia para la especialidad en Argentina y también, en el resto de Latinoamérica. Asimismo, su actuación en publicaciones científicas lo contó como integrante de los comités editoriales de RUNA, la Revista Internacional de Biología de Poblaciones y la Revista Mexicana de Antropología Física.

En la Facultad de Filosofía y Letras de la Universidad de Buenos Aires, además de los cargos docentes ya señalados, ha sido Profesor Regular Titular Plenario, Profesor Consulto Titular y Jefe de la Escuela de Posgrado. Su actividad de gestión también ha sido muy intensa, habiendo sido Decano, Jefe de la Sección de Antropología Biológica, Director del Departamento de Ciencias Antropológicas y Vicedirector del Instituto de Ciencias Antropológicas. 
En síntesis su vida, marcada por la pasión por la ciencia, por la educación pública y su compromiso político, ha sido un ejemplo y un modelo a seguir. El aporte a la comprensión de nuestra historia se plasmó recientemente a través su libro: "El mestizaje en la Argentina" y lo sobrevive, siendo parte del legado que nos deja a los que tuvimos la enorme fortuna de conocerlo y compartimos con él diferentes momentos de su trayectoria.

Docente ejemplar, formador metódico, investigador riguroso $\mathrm{y}$ exigente pero justo $\mathrm{y}$ paciente, compañero, amigo, disfrutaba enormemente de su trabajo, de sus clases y de los encuentros, siempre con una sonrisa cuando finalmente se llegaba a la conclusión que esperaba e imaginaba. Raúl siguió yendo a trabajar hasta el último día que pudo, sin más obligación que las que él mismo se ponía, sufriendo por los atropellos a la investigación y a la universidad de estos tiempos, y diciendo "hay que seguir, no hay que aflojar". Sentía y profesaba verdadera pasión por lo que hacía, soñando, siempre, con un país más justo. Maestro, cuánto se lo va a extrañar!

$$
\text { Sergio Avena }{ }^{1,2,3} \text { y Cristina Dejean }{ }^{1,2}
$$

Bonomo M. y Prates L. (2019). Historias y voces de la Arqueología en el Museo de La Plata. Sociedad Argentina de Antropología (ms).

Ciclo de Encuentros Trayectorias" del Colegio de Graduados de Antropología (2013). Entrevistadoras: Soledad Gesteira, Mercedes Hirsch y Soledad Torres Agüero. http://cga.org.ar/trayectorias-30-francisco-raul-carnese

\footnotetext{
${ }^{1}$ Sección de Antropología Biológica, ICA, Facultad de Filosofía y Letras, UBA

${ }^{2}$ Laboratorio de Antropología Biológica UBA-CEBBAD, $U$. Maimónides

${ }^{3}$ CONICET
} 